\title{
Wiki Uygulamalarına İletişimsel Yaklaşım İle Bir Model Önerisi
}

\section{Offering A Communicational Approach Model To Wiki Applications}

\author{
Dr. Çiğdem Aytekin \\ Marmara Üniversitesi Mühendislik Fakültesi \\ cigdem.aytekin@marmara.edu.tr
}

\begin{abstract}
ÖZET
Yeni nesil internet akım olarak da ifade edilebilecek Web 2.0 teknolojileri, çok noktadan çok noktaya iletişim modelinin alt yapısını oluşturmakta ve Web 1.0 döneminde içeriği tüketen kullanıcıların artık içerik de sağlar olmalarnna firsat vermektedir. Benzer konularda ilgisi olan bireyler bu teknolojiler ile sağlanan uygulamalar üzerinde bir araya gelmekte ve etkileşim içinde bulunmaktadır. Wiki'ler bu uygulamalardan biridir. Yazi-sesgörüntü formatındaki dosyaların birlikte üretim ve paylaşımına dayanan wiki uygulamaları, günümüzde farkh amaçlarla bir araya gelen topluluklar tarafindan ortak bir bilgi platformu yaratmak üzere geniş ölçüde kullanılmaktadır. Wiki uygulamaları günümüzde, bu özellikleriyle, geniş toplulukların işbirliğini ve birlikte üretimini mümkün kılarak yeni bir iletişim modeli yaratmakta ve çok noktadan çok noktaya özelliğiyle geleneksel kitle iletişim modellerinin karşısında yer almaktadır. Bu doğrultuda, çalışmada, wiki uygulamalarn için iletişim bilimi yaklaşımıyla bir model önerisinde bulunulmuştur. Burada model oluşturmada amaç, bir kitle iletişim aracı olarak kabul edilebilecek internetin web 2.0 dönemi ile birlikte karmaşıklaşan yapısını açılamaya yardımo olmak ve wiki uygulamalar için iletişim öğelerini temel unsurlar bazında inceleyerek durumun genel bir resmini vermektir.
\end{abstract}

Anahtar Kelimeler: Wiki, Web 2.0, Etkileşim, İletişim Modeli

\begin{abstract}
Web 2.0 technologies, which can be defined as new generation internet, builds up the infrastructure of multicentered multipoint communication model and allows users to become creators of content, once who were only making use of the content provided for them with Web 1.0. Users who have common interests meet and interact on the applications created by making use of these technologies. Wiki's are examples of these applications. Wiki applications, which are based on creation and sharing of the content in audio, video and text formats are used to form information platforms widely. Wiki applications with these features allow cooperation and coproduction of wide groups and make a new communication model and become an alternative to traditional modes of public communication. In this regard, a new model of wiki applications is suggested in line with the communication science approach. The aim of shaping the model is to explain the structure of internet becoming more and more complex with Web 2.0 and to brief about the framework by analyzing the basics of communication for wikis.
\end{abstract}

Keywords: Wiki, Web 2.0, Interaction, Communication Model 


\section{GİRIŞ}

İletişim teknolojileri bilgisayar teknolojisinden çok daha uzun bir geçmişe sahiptir. Bilginin iletiminde elektriğin ideal bir teknik olduğunun anlaşılması çok uzun sürmemiştir, telekomünikasyonda elektriğin kullanılması 150 yıllık bir geçmişe dayanır. Bu süreç içerisinde her yirmi yılda iletişim alanında önemli bir aşama kaydedilmiştir: 1850'lere doğru telgraf, 1850-1880 arasında telefon, 1900'e doğru elektromanyetik dalgalarla iletim, 1920-30 arası radyo, 1950-60 arası televizyon teknolojisi gelişmiş, son olarak 1970 yılından başlayarak yeni medya teknolojileri kullanılmaya başlanmıştır (Balle, F., Eymery G., 1995). Ancak 70'lerde değinilen anlam, 90'larda müthiş bir ivme kazanan bilgisayar ve internet teknolojisi ile birlikte genişlemiş ve farklı boyutlara ulaşmıştır (Dilmen, N.E., 2007).

Yeni teknolojilerle beraber artık yeni bir iletişim modelinden söz edilmektedir: "Kitleden Kitleye İletişim (many-to-many)" (Livingstone S., 2004). Bu modelde bireyler internet ortamında oluşturdukları gruplarla kitleleri meydana getirmekte ve etkileşim içinde bulunmaktadır. İnternet, etkileşimli yapısı sayesinde eş zamanlı ve karşılıklı iletişimi mümkün kılar (Gibson, R., Ward S., 2000). İnternetin, teknik altyapısı ve kullanılan yazılımlarıyla birlikte kitle iletişim araçlarına özgü hiyerarşik, bir merkezden birçok kişiye uzanan eski iletişim modeli yerine simetrik, birçok kişiden yine birçok kişiye uzanan yeni, esnek, demokratik, ağ üzerinden katılımı olanaklı kılan bir iletişim modeli temsil ettiğini ileri süren görüşler sıkça dile getirilmektedir (Törenli, N., 2005).

Yeni nesil internet akımı olarak da ifade edilebilecek Web 2.0 teknolojilerinin bu iletişim modelinin alt yapısını oluşturduğu ve bu yolla birçok alanda küresel değişimler yarattığı söylenebilir. Bu sayede eskiden statik yapıda olan web sayfaları, artık kullanıcı tarafından yaratılan dinamik sayfalar haline gelmiş ve bu anlamda bir evrim geçirerek demokratikleşmiştir. Benzer konularda ilgisi olan bireyler bu teknolojiler ile sağlanan uygulamalar üzerinde bir araya gelmekte ve etkileşim içinde bulunmaktadır.

Web 2.0, O'Reilly Media tarafından 2004'de kullanılmaya başlayan bir sözcüktür ve ikinci nesil internet hizmetlerini, yani internet kullanıcılarının ortaklaşa ve paylaşarak yarattığı sistemi tanımlar. Ya da basit bir dille vikipedi, youtube, flickr, del.icio.us, ekşi sözlük, pilli network, facebook vb. gibi kullanıcıların diğer kullanıcılar için ziyaret ettikleri internet siteleri veya kullandıkları programlardır (Vikipedi, 2010). Web 1.0 döneminde içeriği tüketen kullanıcılar, Web 2.0 dönemi ile birlikte artık içerik sağlar olmuşlardır. İsteyen herkes ağ sayesinde yaratılan bu sosyal ortamda yer alabilir.

Bu çalışmada, Web 2.0 ile sağlanan bir sosyal ağ uygulaması olarak Wiki'ler incelenmiş ve iletişimsel bakış açısı ile değerlendirmeler yapılarak bir model önerisinde bulunulmuştur.

\section{WIKI UYGULAMALARI VE ÖZELLİKLERI}

Birçok web tabanlı içerik hazırlama sistemi, içeriğin bir düzenleyici üzerinde çevrimdışı olarak hazırlanması ve sunucuya aktarılması yöntemiyle çalışır. Bu yöntemin oluşturduğu sıkıntıların başında, her bir konunun tek kişi tarafından hazırlanması ve diğer 
kişiler tarafından yapılabilecek yardımın asenkron olarak gerçekleşmesi gelmektedir. Bu duruma örnek olarak "Tek Web Yöneticisi Sendromu” adı verilen durum gösterilebilir. Buna göre web sayfasında istenen en ufak bir değişiklik ihtiyacı bile içeriği hazırlayan yöneticiye ulaştırılmakta ve bu durum içeriğin mükemmelleşmesinde büyük bir engel oluşturmaktadır. Wiki uygulamaları bu sınırlılığı ortadan kaldırmaktadır (Özkütük, S., 2007).

Adı WikiWikiWeb olan ilk wiki, 1995 yılında Ward Cunningham tarafından geliştirilmiştir. Kodların anında yayınlanmasını sağlayacak nispeten basit bir program amacıyla yola çıkan Cunningham, programcıların ihtiyaçlarını daha iyi karşılayacak yeni bir dokümantasyon sistemi için araştırma yapmıştır. Hedef, doküman geçmişinde daha kolay değişiklikler yapmak için tüm düzenleme adımlarını otomatik olarak dokümente edecek bir programdır. Sonunda ilk wiki server bu şekilde online olmuştur ve o zamandan beri kullanımdadır (Ebersbach, A., Glaser, M., Heigl, R., Warta, A., 2008).

Ducamp'ın isim babalığı yaptığı Craowiki adlı web sitesi de, dünyaca ünlü wiki'lerden sadece birisidir. Ducamp'ın açıklamasıyla, "Burası, farklı profillerden insanların bir araya geldikleri adeta nitelikli bir çalışma bürosu gibidir." Ayrıca bu iki kökensel örnek dışında, isimlerinden sıkça söz ettiren belli başlı wiki siteleri arasında üçünün daha altı çizilebilir: Adminet, Meatball ve Wikipedia (Köse, H., 2008).

Wiki ismi Hawaii dilinde çabuk anlamına gelen wikiwiki kelimesinden türetilmiştir. En basit tanımıyla wiki, insanların web sayfaları üzerinde istediği gibi düzenlemeler yapmasına izin veren bilgi sayfaları topluluğudur. Gruplar, wiki sayesinde kolayca geniş dokümantasyonlar oluşturabilir ve bu belgeler arasındaki sürüm farklılıklarını takip edebilir. Sayfalar arasındaki bağlantılar ve sayfa biçimlemeleri sistem tarafından otomatik olarak yapılandırılacağından, bilgiye erişme ve bilgi belgeleme, wiki ile son derece kolaylaşmaktadır. Bu işlemler için web site yöneticileri kolaylıkla gerekli yetkilendirme düzeyleri ayarlayabilirler (Özkütük, S., 2007). Wiki uygulamalarında ayrıca, mevcut veriler ve bunların değiştirilmesi ile ilgili tartışmalar yapılabilmekte, bu tartışmalar ve değişikliklerin kaydı tutulabilmektedir. Bu işlem ve etkileşim kolaylığı wiki'yi yoğun yazarlık işbirliği için etkili bir araç haline getirmiştir (Karaman, S., 2008).

Diğer yandan wiki'ler, yapısal olarak blog sayfalarıla benzerlikler gösterse de, onlar gibi tek bir yazara sahip değildir. Blog yazılarında ziyaretçiler, yazarın önceden yazmış olduğu mesajlara yorum gönderebilirler, ancak var olan içeriği değiştiremezler. Wiki sayfalarında ise herkes yazardır ve sitede yer alan "düzenle" seçeneğiyle yazılmış olan bir metni değiştirebilirler. Ayrıca wiki'ler, sadece tanımların değil, hikâye kitaplarının, makalelerin, haber kaynaklarının, fotoğraf-ses-video gibi medya kaynaklarının da bulunduğu geniş bir ortamdır (Altun, A., 2005).

Geleneksel web içerik geliştirici modellerden çok farklı olan wiki uygulamaları, geleneksel web sitelerinde yapılamayan içerik yaratmayı teşvik eder. Ayrıca, uzman bir görüşe karşı fikir de geliştirilebilir. Bununla beraber wiki'ler her durum için en iyi çözüm değildir. Bazı çevreler, iyi niyetli olmayan yaklaşımlarla içeriğin bozulabileceğini ve yıkıcı bir teknoloji olarak kontrolden çıkabileceğini düşünmektedir. Ancak sadık kullanıcılar izleme yöntemleri sayesinde bu problemle başa çıkabilir. Eğer çevrimiçi bir grup ile işbirliği 
yapmak adına bir yola ihtiyaç duyuluyorsa ve grup üyelerinin içeriğe yeteri kadar katkı sağlayacağ1 konusuna güveniliyorsa, bu durumda bir wiki idealdir. Wiki'ler, bir grubun kolektif bilgisi üzerinde sermaye için bir bilgi deposu yaratmada ya da zaten mevcut veritabanına değer katmada en iyi araçtır (Farkas, M.G., 2007).

Wikimedia ise, çoklu katılımla geliştirilen projelerden oluşan büyük bir projedir. Kâr amacı gütmeyen "Wikimedia Vakfı" isimli vakıf şirketi tarafından yürütülmektedir. Örneğin, Wikipedia bu projenin bir parçasıdır (Vikipedi, 2011). Güncel olan Wiki Projeleri Tablo 1'de açıklamaları ile yer almaktadır.

Tablo 1: Wiki Projeleri

\begin{tabular}{|l|l|l|}
\hline \multicolumn{1}{|c|}{ Merkez } & \multicolumn{1}{c|}{ Türkçe Site } & \multicolumn{1}{c|}{ Açılama } \\
\hline Wikipedia & Vikipedi & 250'den fazla dilde ansiklopedi \\
\hline $\begin{array}{l}\text { Wikimedia } \\
\text { Commons }\end{array}$ & $\begin{array}{l}\text { Türkçe } \\
\text { Commons }\end{array}$ & 8.000.000'den fazla resim, ses ve video deposu \\
\hline Wiktionary & VikiSözlük & $\begin{array}{l}\text { Çok yönlü bir sözlük - 210.000'den fazla sözlük } \\
\text { maddesi }\end{array}$ \\
\hline Wikibooks & VikiKitap & Eğitim amaçlı kılavuz ve ders kitapları \\
\hline Wikisource & Vikikaynak & $\begin{array}{l}\text { Serbest kaynaklı kitap, belge, metinleri ve } \\
\text { çevirileri }\end{array}$ \\
\hline Wikiquote & VikiSöz & Atasözleri ve çeşitli özlü sözler \\
\hline Wikispecies & VikiTür & Tüm hayat formlarının dizini. \\
\hline Meta-Wiki & Türkçe Meta & Wikimedia projesinin koordinasyonu \\
\hline Wikinews & Vikihaber & $\begin{array}{l}\text { Birçok ülkeden insanların oluşturduğu } \\
\text { haberler }\end{array}$ \\
\hline Wikiversity & -yok- & Viki Üniversite - Açıöğretim \\
\hline
\end{tabular}

Kaynak: Vikipedi, WikiMedia, 24.08.2011, http://tr.wikipedia.org/wiki/Wikimedia Erişim tarihi: 25.08.2011.

Yazılı ve görsel belgelerin kolektif üretim ve paylaşıma dayalı bir modelini oluşturan wiki uygulamaları, günümüzde birçok topluluk tarafından, kolektif bazı tasarılar ve amaçlar üzerinde işbirliği yapmak, eylemde bulunmak ya da enformasyon akışının hızını artırmayı sağlamak için kullanılmaktadır. Bu özellikleriyle wiki'ler, hızlı haberleşmeyi sağladıkları gibi, merkezi olmayan ve dolayısıyla da bir ölçüde denetim dışı kalabilen yeni bir enformasyon havuzunun yaratımına da kaynaklık etmektedir (Köse, H., 2008).

İş alanlarında da wiki uygulamalarından büyük ölçüde yararlanılmaktadır. URL adresinde wiki kelimesi bulunan işletmelerin sayısı günden güne artmaktadır. Bu sayfaların bir kısmı müşteri ile etkileşim gerçekleştirme amaçlı olarak yer alırken, bir kısmı da sponsorluk düzeyinde barındırılmaktadır. Bu nedenle aşağıdaki bölümde işletmelerin gerçekleştirdiği wiki uygulamalarına örnekler verilmiştir. 


\section{3. İŞ ALANLARI İÇIN WIKI UYGULAMALARI}

Wiki toplulukları farklı alanlarda yayılırken, iş dünyasında önce şüpheyle karşılanmıştır. Herkese açık bir sistem olması bilgilere kolayca ulaşılmasını sağlamaktadır. Ama başı sonu belli olmayan, kural koyucular tarafından kontrol edilemeyen açı bir platformu kullanmak ne kadar güvenilir ve sağlıklı olabilir? Yine de wiki, kurumsal yaşamdaki yerini almıştır. Sistemin çok ucuza kurulmasının, hatta bilgi-işlem departmanlarının desteğine gerek kalmadan bu tür toplulukların oluşabilmesinin bunda büyük etkisi vardır. Aynı şirket e-posta adreslerine sahip olmadan önce çalışanların kendi jenerik e-posta adreslerini iş amaçı kullanmaya başlaması gibi wiki de çeşitli yollardan şirketlere nüfuz etmiştir. Wiki'ler özellikle proje yöneticileri, küçük çalışma ekipleri gibi hiyerarşik kontrol yapıları yerine daha paylaşımcı sistemlerin yararına inanan kişiler tarafından tercih edilmiştir. Dolayısıyla, wiki yazılımlarını kendi işletme ihtiyaçlarına uyarlamaya başlayan şirketlerin sayısı artmaktadır. www.SocialText.com işletmelere bu yönde wiki hosting hizmeti veren şirketlerden biridir. Yararlanan işletmeler sonucun sadece daha yakın bir işbirliği değil, aynı zamanda resmiyetten uzak, doğal bir şekilde oluşan bir kurum belleğinin yaratılması olduğunu belirtmektedir. E-posta, ajanda ve diğer iş uygulamalarını wiki üzerinden izlemek mümkündür. Üretim programlarını ve sektördeki gelişmeleri takip etmek için dahi wiki kullanan işletmeler bulunmaktadır. Walt Disney, Inktomi ve Motorola ise wiki uygulamaların benimseyen işletmelerden sadece bazılarıdır (http://www.capital.com.tr, 2010).

IBM, IBM Web sitelerini kullanmak için kayıt yaptıran üyeler arasında çevrimiçi paylaşımın ve işbirliğinin yapılmasını sağlamak üzere bazı IBM Web siteleri üzerinde wiki'leri de kullanıma sunmaktadır (http://www.ibm.com, 2010).

Motorola ise, http://motorolaq.wetpaint.com/ adresindeki "Motorola Q Wiki" sitesini “Moto $Q$ " ürünü için kullanıcılarının hizmetine sunmuştur. Bireyler "Moto $Q$ Smartphone" larına ait her türlü bilgiyi, deneyimlerini bu sitede paylaşmaktadır. Sitede ayrıca tartışmalar, fotoğraflar, videolar ve haberler gibi sekmeler de yer almaktadır. Böylece bir yandan ürüne ait kullanıcı bilgisine ve görüşlerine kolay yoldan ulaşılabilmekte, diğer yandan da deneyimli kullanıcıların uygulamalarından diğer kullanıcıların yararlandırılması sağlanmaktadır.

Walt Disney de, http://disney.wikia.com/wiki/The DisneyWiki adresinde bulunan Disney wiki uygulamasını Walt Disney ile ilgili her şey için işbirlikçi bir ansiklopedi olarak tanıtmakta ve kullanıcılarına Disney ile iştirakleri (filmler, film şirketleri, televizyon ağları, karakterler ve daha fazlası) üzerinde makale bulma, yaratma ve düzenleme fırsatını vermektedir.

PBworks adıyla kişisel, eğitim ve iş alanları için çözümler sunan PBwiki, "Müşteri İlişkilerini Geliştirmek İçin PBworks Extranetlerini Kullanma" başlıklı yazısında şu açıklamayı yapmaktadır (http://pbworks.com, 2010): Son yirmi yılda işletmeler Müşteri İlişkileri Yönetimine trilyonluk yatırımlar yaptılar. Ancak bu yatırımın bir kısmı, "İlişkileri Yönetilen Müşteriler" için belirgindir. Müşteri İlişkileri Yönetimi araçları aşırı bir biçimde içe dönüktür. İşletmeler, sadece müşteri temsilcisinin verdiği hizmet çerçevesinde müşteri ile 
temasın kapsamlı bir görüntüsünü verir. Aslında müşterileri için hiç bir şey yapmamış durumdadırlar. Müşteriler, müşteri tabanına bir girişten çok daha fazlasını ifade eder ve bir müşteri ile ilişki, gelmiş ve gelecek e-postaların toplamından çok daha fazladır. Müşterilerin farklı bilgilerine ulaşabilme amacıyla tüm telefon aramaları ve gönderilen e-postalar düşünüldüğünde ve sonra yeniden ne sıklıkla göndermek durumunda olunacağ1 düşünüldüğünde, işbirlikçi bir müşteri extraneti sağlamanın çözüm olacağı söylenebilir. Bu extranet satış ekibinin Müşteri İlişkileri Yönetimi için yaptığını yapar, müşteri ilişkilerini yönetmek için merkezi bir alan sağlar. Bir PBworks, işletmelere ve müşterilere ilişkiyi birlikte yönetmek için işbirlikçi bir çevre ile bir müşteri extraneti sağlar. Sonuç, daha fazla memnun müşteri ve yöneticiler için daha az çalışma demektir. Böylece müşteri ile iletişimler geliştirilebilir, doküman ve dosyalar paylaşılabilir, yararlı bilgiler depo edilebilir, daha etkin karşılaşma akışı gerçekleştirilebilir ve aradaki mesafelere karşı çalışılabilir.

Wiki uygulamalarının işletmelere sağladığı/sağlayacağı yararlar doğrultusunda gelecekte çoğu işletmenin ilgili etik kurallar çerçevesinde kendi wiki sayfalarını oluşturarak kullanıma açacağı ve hatta wiki kelimesinin url adreslerinde bu çerçevede standart olarak yer alabileceği söylenebilir.

\section{WIKI UYGULAMALARINA İLETIŞ̧iMSEL YAKLAŞIM İLE BíR MODEL ÖNERISI}

Wiki uygulamaları günümüzde, geniş toplulukların işbirliğini ve birlikte üretimini mümkün kılarak yeni bir iletişim modeli yaratmakta ve çok noktadan-çok noktaya özelliğiyle geleneksel kitle iletişim modellerinin karşısında yer almaktadır.

İletişim sürecinin temel unsurları ile wiki'lerin özellikleri karşılaştırıldığında, wiki'lerin aşağıda belirtilen işlevlerinin bulunduğu görülmektedir: incelenebilir:

Gönderici: Göndericiler, wiki uygulamasının niteliği ile ilgili olarak iki kısımda

- Örneğin, Vikipedi uygulamasında gönderici, web sitesinin içeriğinden ve yapısından kendilerini sorumlu hisseden kişilerdir. Bu kişiler yaptıkları sürekli güncellemelerle ve yarattıkları yeni maddelerle gönderici rolündedir. Maddeleri değiştirmek için oturum açmak şart olmamakla birlikte, sağlanan yetkiler bakımından hesap sahibi bir kullanıcı olmanın iyi bir fikir olduğu söylenebilir.

- Örneğin, Motorola Q Wiki uygulamasında olduğu gibi iş alanlarına yönelik wiki uygulamalarında gönderici, smartphone'una ait deneyimlerini yol göstermek gibi amaçlarla diğer kullanıcılarla paylaşan kişilerdir.

Mesaj: İletilecek mesaj, zaman ve mekân bağımsız olarak gönderilebilmektedir. Mesajlar metin içerikli olabileceği gibi ses, hareketsiz görüntü ve hareketli görüntü biçiminde de olabilir. 
İletişim Kanah: Kanal olarak, web sayfasından daha hızlı ve kolay güncellenebilen ve farklı formattaki mesajların yüklenebileceği altyapıya izin veren wiki ortamı kullanılmaktadır.

Alıcı: Mesajları okuması hedeflenen kişilerdir. Bu bakımdan değerlendirildiğinde, göndericilerin de zaman zaman alıcı olabildiği söylenebilir. Ayrıca mesajların herkese açık olması, potansiyel hedeflerin de mesaj alıcısı konumuna geçmesini sağlar.

Geri Bildirim: Wikiler statik web sayfalarına göre dinamik yapıda olup "etkileşimli olma" özelliğine sahiptir. Bu özellik, iletişimin temel unsurlarından olan geri bildirim açısından büyük ölçüde önemlidir. Zira geleneksel kitle iletişim araçlarında geri bildirim sınırlıdır. Oysa wiki uygulamalarında iletişim iki yönlüdür (göndericiden alıcıya, alıcıdan göndericiye) ve özellikle tartışma sayfaları etkileşime katkı sağlayarak geri bildirim sinırlılığına çözüm getirmektedir.

Modeller, herhangi bir yapı veya sürecin başlıca öğelerini ve bu öğeler arasındaki ilişkileri göstermeyi amaçlar. Karmaşık veya belirsiz olabilecek enformasyonu basitleştirilmiş şekliyle vererek açıklamaya yardımcı olur. Bu nedenle kaçınılmaz olarak eksiktir ve bazı gizli önkabuller içerir (McQuail, D., Windahl, S., 2005). Tarihsel sürecinde iletişim kavramını tam olarak açıklama gereksinimi nedeniyle farklı kriterler esas alınarak birçok model geliştirilmiştir. Ancak bir kitle iletişim aracı olarak kabul edilebilecek internetin web 2.0 dönemi ile birlikte iletişim büsbütün kompleks bir hal almıştır. Önerilen modelin, bir web 2.0 uygulaması olan wiki'ler için, temel unsurlar bazında bu kompleks yapının anlaşılmasına katkı sağlayacağı düşünülmektedir.

Wiki uygulamaları için önerilen kitle iletişim modeli Şekil 1'de, yukarıda bahsedilen beş temel unsur bazında gösterilmiştir. Her bir unsur, kendisini tanımlayan özel şekillerle temsil edilmektedir:

- Gönderici: Her bir gönderici aslında kendi içinde bir bilgi grubu oluşturmaktadır. Gönderici sayısında bir sınırlama yoktur, tercihi bu yönde olan her kişi ilgili bilgi grubunda gönderici olabilir. Okuma-EklemeDeğiştirme-Silme görevlerini yerine getirirler.

- Mesaj: İletişim araçları tarihsel süreçte yazı, ses, görüntü teknikleri ile yer almıştır. Bu nedenle bahsedilen teknikler döngüsel ilerlemede mesajla ilişkiyi göstermek için kullanılmıştır.

- İletişim Kanah: Kanal olarak wiki uygulamalarını belirleyen sıralı görevler, kitle iletişim aracı ve geri bildirim aracıdır.

- Alıcı: Alıcılar bir anlamda dişliler gibi birbirine kenetlenmiş kişilerdir ve okuma görevini yerine getirirler. 


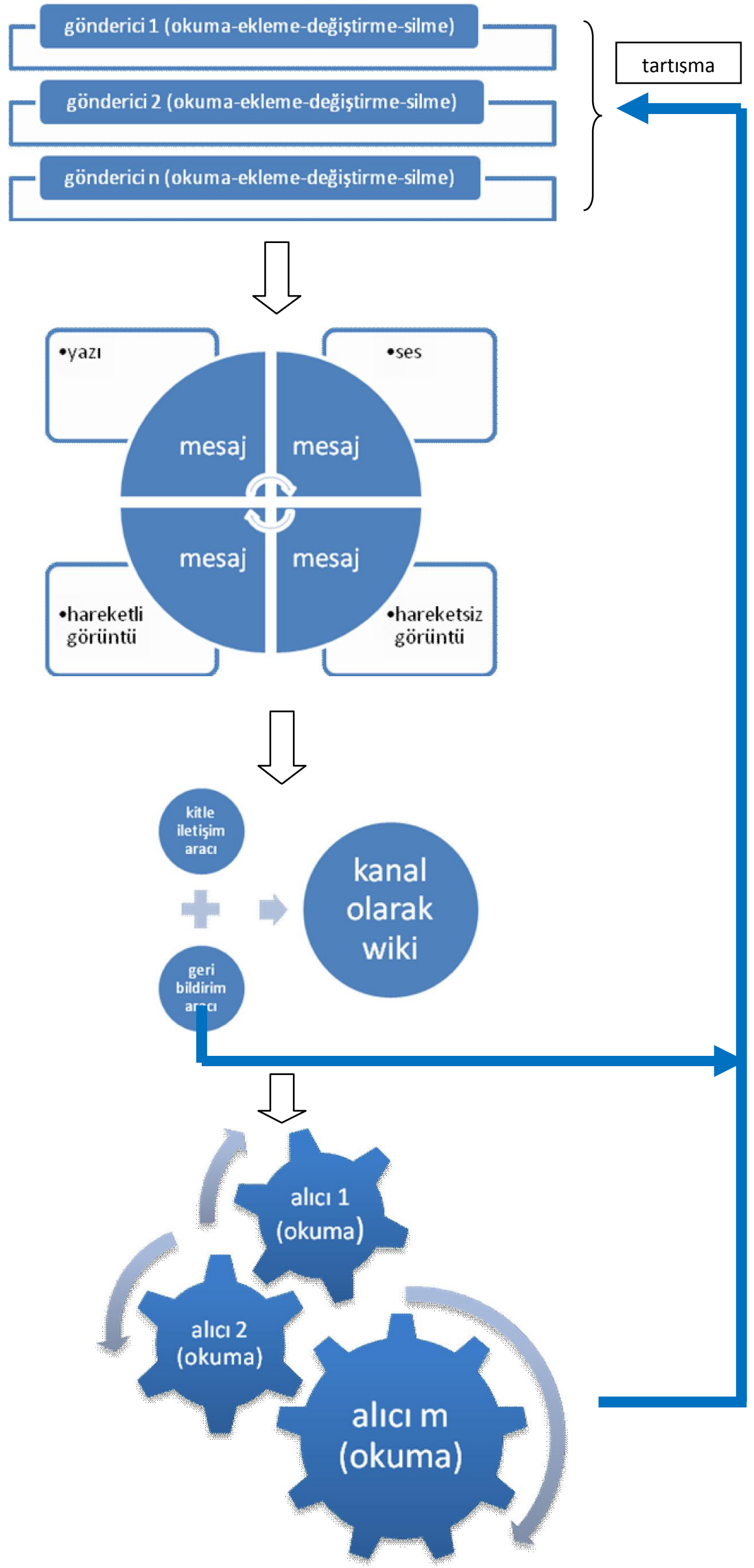

Şekil 1: Wiki Uygulamaları İçin Önerilen Kitle İletişim Modeli 


\section{SONUÇ}

Yeni nesil internet akımı olarak da ifade edilebilecek Web 2.0 teknolojileri, çok noktadan çok noktaya iletişim modelinin alt yapısını oluşturmakta ve Web 1.0 döneminde içeriği tüketen kullanıcıların artık içerik de sağlar olmalarına fırsat vermektedir. Benzer konularda ilgisi olan bireyler bu teknolojiler ile sağlanan uygulamalar üzerinde bir araya gelmekte ve etkileşim içinde bulunmaktadır. Wiki'ler bu uygulamalardan biridir. Yazı-sesgörüntü formatındaki dosyaların birlikte üretim ve paylaşımına dayanan wiki uygulamaları, günümüzde farklı amaçlarla bir araya gelen topluluklar tarafından ortak bir bilgi platformu yaratmak üzere geniş ölçüde kullanılmaktadır.

İş alanlarında da wiki uygulamalarından büyük ölçüde yararlanılmaktadır. URL adresinde "wiki" kelimesi bulunan işletmelerin sayısı günden güne artmaktadır. Bu işletmeler, wiki uygulamaları sayesinde hem müşterileri ile yakın bir işbirliği içinde olduklarını belirtmekte, hem de doğal bir şekilde oluşan kurum belleğinin yaratılmasından söz etmektedir.

Wiki uygulamaları günümüzde, bu özellikleriyle, geniş toplulukların işbirliğini ve birlikte üretimini mümkün kılarak yeni bir iletişim modeli yaratmakta ve çok noktadan çok noktaya özelliğiyle geleneksel kitle iletişim modellerinin karşısında yer almaktadır. Bu doğrultuda, çalışmada, wiki uygulamaları için iletişim bilimi yaklaşımıyla bir model önerisinde bulunulmuştur. Tarihsel sürecinde iletişime ilişkin farklı türler için farklı modeller geliştirilmiştir. Burada model oluşturmada amaç, bir kitle iletişim aracı olarak kabul edilebilecek internetin web 2.0 dönemi ile birlikte karmaşıklaşan yapısını açıklamaya yardımcı olmak ve wiki uygulamaları için iletişim öğelerini temel unsurlar bazında inceleyerek durumun genel bir resmini vermektir. 


\section{KAYNAKLAR}

Altun Arif, (2005), Eğitimde İnternet Uygulamaları, Ankara, Anı Yayıncılık, 66.

Balle Francis, Eymery Gerard, (1995), Yeni Medyalar, Mehmet Selami Şakiroğlu (çev.), İstanbul, İletişim Yayınları, 18.

Demirel Gülşen, Nedir bu wiki?, Capital Aylık İş ve Ekonomi Dergisi, 01.06.2003, http://www.capital.com.tr/haber.aspx?HBR_KOD=865 Erişim tarihi: 09.06.2010.

Dilmen Necmi Emel, (2007), Yeni Medya Kavramı Çerçevesinde İnternet Günlükleri-Bloglar ve Gazeteciliğe Yansımaları, Marmara İletişim Dergisi, No: 12, Şubat 2007, 114.

Ebersbach Anja, Glaser Markus, Heigl Richard, Warta Alexander, (2008), Wiki: Web Collaboration, 2nd edition, Springer-Verlag Berlin Heidelberg, 12.

Farkas Meredith Gorran, (2007), Social software in libraries: building collaboration, communication, and community online, second printing, New Jersey, Information Today Inc, 84 .

Gibson Rachel, Ward Stephen, (2000), A Proposed Methodology For Studying The Function And Effectiveness Of Party And Candidate Web Sites, Social Science Computer Review, 18, 3, 301-319.

Karaman Selçuk, Yıldırım Serkan, Kaban Abdullatif, (2008), Öğrenme 2.0 Yaygınlaşıyor: Web 2.0 Uygulamalarının Eğitimde Kullanımına İlişkin Araştırmalar ve Sonuçları, inettr'08, XIII. Türkiye' de İnternet Konferansı Bildirileri, Orta Doğu Teknik Üniversitesi, Ankara, 22-23 Aralık 2008, 35-40.

Köse Hüseyin, (2008), İnternette "Açık" ve Demokratik Yayıncılık: "Sanal Ortam Günlükleri” ve "Wiki"ler, Marmara İletişim Dergisi, 13, 83-93.

Livingstone Sonia, (2004), The Challenge Of Changing Audiences Or, What is The Audience Researcher To Do in The Age Of The Internet?, European Journal Of Communication, $19,1,75-86$.

McQuail Denis, Windahl Sven, (2005), İletişim Modelleri, Konca Kumlu (çev.), İstanbul, İmge Kitapevi, 16.

Özkütük Serdar, (2007), Yüksek Öğretimde Ortaklaşa Oluşturulan Ders Notları için Wiki Tabanlı İşbirliği Platformu Uygulaması, Akademik Bilişim’07, IX. Akademik Bilişim Konferansı Bildirileri, Dumlupınar Üniversitesi, Kütahya, 31 Ocak - 2 Şubat 2007, 219. 
PBWorks, Use PBworks Extranets To Improve Customer Relationships, http://pbworks.com/content/biz-customer-extranet?utm campaign=navtracking\&utm source=Top navigation Erişim tarihi: 10.06.2010.

Sosyal Bilgi İşlem Ortamındaki Bilgilerin Kullanılması, http://www.ibm.com/privacy/details/tr/tr/ Erişim tarihi: 10.06.2010.

Törenli Nurcan, (2005), Yeni Medya, Yeni İletişim Ortamı, Ankara, Bilim ve Sanat Yayınları, 156-159.

Vikipedi, WikiMedia, 24.08.2011, http://tr.wikipedia.org/wiki/Wikimedia Erişim tarihi: 25.08.2011.

Vikipedi, Web 2.0, 04.03.2010, http://tr.wikipedia.org/wiki/web 2.0 Erişim Tarihi: 18.03.2010. 